\title{
El Contrapunto de Fierro y el Moreno
}

Hasta el canto 28 de La vuelta de Martín Fierro se suceden cuatro "relaciones": de Martín Fierro, del Hijo Mayor y del Hijo Segundo de Fierro, y de Picardía, hijo de Cruz. La historia del primero (cantos I-10) evoca los cinco años pasados entre los pampas, en cuyos toldos habían buscado refugio Fierro y Cruz al final de El gducho Martín Fierro. Los cristianos viven entre los salvajes como "cautivos"; desde este punto de vista se pormenorizan con abundancia las costumbres bárbaras de los indios. La muerte de Cruz y el rescate de la Cautiva disponen el final de ese período. De nuevo en la frontera, Fierro informa sobre situaciones pendientes en el argumento de la parte primera (canto 11). A propósito de la muerte del negro, se declara: "Me dijo, a más, ese amigo, / Que anduviera sin recelo, / Que todo estaba tranquilo, / Que no perseguía el Gobierno, / Que naides se acordaba / De la muerte del moreno. / Aunque si yo lo maté / Mucha culpa tuvo el negro. / Estuve un poco imprudente, / Puede ser, yo lo confieso, / Pero él me precipitó / Porque me cortó primero; / Y a más me cortó en la cara, / Que es un asunto muy serio" (vv. 1593-1606). En la información general del romance destinado a cubrir los choques del protagonista principal con las autoridades, se instala el episodio del negro, explicado y justificado desde los intereses del matador. ${ }^{1}$

Las tres relaciones restantes parten de la situación de orfandad en que han quedado sus protagonistas; unificado el punto de partida de las trayectorias vitales, se diversifican las historias. La del Hijo Mayor (can-

1 La actitud del protagonista en el canto VII de El gaucbo Martín Fierro es un obstáculo en el cual tropiezan casi todos los comentaristas del poema. $\mathrm{La}$ explicación del episodio se encuentra en la determinación de Fierro frente a la familia dispersa y el rancho hecho tapera, como consecuencia de los años pasados en el fortín: "Yo he sido manso primero, / $Y$ seré gaucho matrero / En mi triste circunstancia, / Aunque es mi mal tan projundo; / Nací y me he criao en estancia, / Pero ya conozco el mundo" (vv. 1099-1104). Al desarraigarse de la sociedad, su rebeldia se manifiesta en las dos muertes que comete: la del moreno en un baile y la del pendenciero en un boliche. Son actos que rubrican su matretía. La confusión de sentimientos del cantor es marcada por los cambios estróficos de los cantos VII (cuartetas y una décima) y VIII (dos octavas y sextillas). 
to 12) se concentra en una sola experiencia, los años en la penitenciaría. Las muchas aventuras del Hijo Segundo (cantos 13-19) desembocan en el servicio de frontera, con una notificación que evita los pormenores sobre ese período de su existencia. En el romance del canto 20 se presenta a Picardía; las desdichas y las trapisondas del hijo de Cruz (cantos 21-28) concluyen también en la condición de soldado de fortín; etapa en la que se comentan con abundancia los enredos y acomodos de los personajes con mando. ${ }^{2}$

El Hijo Mayor, el Hijo Segundo y Picardía ilustran por extenso la situación social determinada por el impuesto desarraigo de Fierro y de Cruz. Cerrado este ciclo, el romance del canto 29 presenta a un protagonista nuevo: "Relación en que aparece un negro cantor". El desafío que éste dirige a Martín Fierro se manifiesta con un alarde fantasioso, sin necesidad de palabras: "Y como quion no hace nada/O se descuida de intento / (Pues siempre es muy conocido / Todo aquel que busca pleito),/ Se sentó con toda calma, / Echó mano al estrumento / Y ya le pegó un rajido; / Era fantástico el negro, / Y para no dejar dudas / Medio se compuso el pecho" (vv. 3897-3906). El provocado acepta el reto y el canto 30 presenta la payada de contrapunto entre Fierro y el Moreno. ${ }^{3}$

2 El relato de Picardia diversifica las experiencias en el fortín, ya presentadas por Fierro en la parte primera del poema (cantos III-VI). Los rasgos dramáticos y la protesta social predominan en el relato de Fierro, aunque no falten episodios de humor acre; el hijo de Cruz refuerza la visión apicarada, sobre la cual se superponen apelaciones de testimonio genérico.

3 Payador es una palabra de difusión rioplatense que nombra a los gauchos cantores probados en la improvisación de relatos sobre su vida, de comentarios sobre sucesos públicos notables, o de temas abstractos, algunas veces propuestos por los oyentes. La payada de contrapunto extendía esas improvisaciones a la competencia de dos cantores, uno que interrogaba y el otro que respondía, y a la recíproca; el público decidía sobre el triunfador. El canto era acompañado con música de guitarra, ejecutada por el mismo payador; muy pocas eran las variantes musicales, apenas un apoyo melódico a la enunciación de los argumentos - las definiciones. Las estancias, las pulperías y las fiestas populares daban ocasión al lucimiento de esas supuestas improvisaciones, regularizadas por la repetición y el sostén de los recursos retóricos; de esta manera cada payador llegaba a tener su repertorio específico. La función de los payadores se extendió desde fines del siglo xviri a las décadas iniciales de la centuria presente. Uno de los epígrafes de El gaucho Martín Fierro evoca al payador a través de la interpretación del uruguayo Alejandro Magariños Cervantes en su poema Celiar; del romance citado importan los cuatro versos finales: "Así el cantor sin curarse / De reglas que no le importan, / Sigue raudo y caprichoso / Su bien comenzada trova". Esta independencia creadora interesó fundamentalmente a los románticos de los dos países del Plata. Posteriormente Lugones hizo del cantor gaucho un equivalente del aedo griego $\mathrm{y}$ del juglar medieval, aplicando el designativo a Hernández, el payador por excelencia; con este procedimiento se justifica el nivel épico de Martin Fierro y sus funciones definitorias en la formación de la nacionalidad (Lugones, Leopoldo. El Payador. Tomo I: Hijo de la pampa. Buenos Aires, Otero y García, 1916). En Martín Fierro se utiliza una vez sola el verbo "payar"; es en el canto de contrapunto y en la voz del Moreno, una vez concluida la competencia de inquisiciones y respuestas: "Y si otra ocasión payamos / Para 
La conexión entre los cantos 29 y 30 está reforzada por la rima; la asonancia $e-o$ del primeto se reitera en algunas sextillas del contrapunto; las mismas vocales reaparecen en las rimas consonantes. Es significativo que correspondan a los nombres de los dos protagonistas del enfrentamiento. Esta relación puede aludir a la cuestión personal que supera los alcances del contrapunto y que se va desenvolviendo a través de las alusiones del Moreno, de inmediato recogidas por Fierro.

La poética del nuevo estilo de cantar que aparece en el poema es desenvuelta por Fierro, en reclamo a la atención del público: "Atiendan, pues, los oyentes / Y cáyense los mirones; / A todos pido perdones, / Pues a la vista resalta / Que no está libre de falta / Quien no está de tentaciones" (vv. 3923-3928). El primer dato de la explicación indica el riesgo del contrapunto en relación con un prestigio que debe comprobarse decisivamente: "A un cantor lo llaman bueno/Cuando es mejor que los piores; / Y sin ser de los mejores, / Encontrándose dos juntos, / Es deber de los cantores / El cantar de contrapunto" (w. 3941-3946). La fama de los cantores es jugada por un enfrentamiento en el cual los oponentes se examinan sobre sus méritos en la exposición de los respectivos repertorios de temas. Un dato complementario distingue la forma de cantar habitual en la juventud de Fierro, antes de que cayeran sobre él las desdichas que lo obligaron a un cambio expresivo: la exposición de sus propias desdichas. El primer estilo - llamado de fantasía- corresponde al canto de contrapunto; el testimoniante, con intención de denuncia, ha sido definido por el cantor en su presentación de la parte segunda: "Yo he conocido cantores / Que era un gusto el escuchar, / Mas no quieren opinar / Y se divierten cantando; / Pero yo canto opinando / Que es mi modo de cantar" (vv. 61-66). La diferencia entre una y otra etapa se relaciona con una situación personal sabida por los oyentes: "Cuando mozo fui cantor, / - Es una cosa muy dicha-- / Mas la suerte se encapricha/Y me persigue costante: / De ese tiempo en adelante / Canté mis propias desdichas" (vv. 3941.3946). En referencia a sus años mozos, Fierro recuerda la duración de los enfrentamientos, prolongados por la inventiva de los payadores: "Y seguiremos si gusta / Hasta que se vaya el día;/Era la costumbre mía / Cantar las noches enteras: / Había entonces dondequiera/Cantores de fantasía" (vv. 3965$3970)$.

que esto se complete, / Por mucho que lo respete / Cantaremos, si le gusta, / Sobre las muertes injustas / Que algunos hombres cometen" (vv. 4451-4456).

Hay bibliografía numerosa dedicada a la actividad payadoresca; de esos libros pueden leerse con provecho: Leumann, Carlos Alberto. La literatura gauchesca y la poesía gaucba. Buenos Aires, Raigal, 1953. Román, Marcelino M. Itinerario del payador. Buenos Aires, Lautaro, 1957. Moya, Ismael, El arté de los payadores. Buenos Aires, P. Berruti, 1959. 
En la presentación del Moreno se suman rasgos complementarios, que ilustran sobre las exposiciones personales previas al contrapunto. Al cabo de una abreviada biografía (vv. 3977-4006) de quien se clasifica como "un pobre guitarrero", el negro sintetiza su trayectoria con la misma condición de que se había gloriado Fierro en su presentación de la parte primera (canto 1).4 La coincidencia con el protagonista primero insiste en las garantías personales aseguradas por la libertad plena: "Pero yo he vivido libre / $Y$ sin depender de naides; / Siempre he cruzado a los aires / Como el pájaro sin nido: / Cuanto sé lo he aprendido/Porque me lo enseñó un flaire" (vv. 4001-4006). La referencia final, el haber tenido como mentor a un fraile, es diversificada por los caracteres de su sapiencia: el saber, "como cualquier otro", el por qué retumba el trueno, el por qué son las estaciones del verano y del invierno, de dónde salen las lluvias, lo que se encuentra en el centro de la tierra y en el fondo del mar, el crecimiento del árbol y el silbido de los vientos. Este repertorio indica que el payador tenía sus temas específicos; apoyo del floreo verbal, condicionado por fórmulas retorizadas. La temática del Moreno se instala en la definición de los fenómenos naturales habitual en los románticos cultos; el sesgo personalizado se fija en el origen sobrenatural de tales hechos.

Los conocimicntos del Moreno imponen una diferencia racial trasladada al plano de la inteligencia: "Cosas que inoran los blancos / Las sabe este pobre negro" (vv. 4023-4024). Este distingo se proyecta sobre el sentido docente destacado por el payador: "De lo que un cantor esplica / No falta qué aprovechar, / Y se le debe escuchar / Aunque sea negro el que cante: / Apriende el que es inorante, / $\mathrm{Y}$ el que es sabio, apriende más. //Bajo la frente más negra/Hay pensamiento y hay vida; / La gente escuche tranquila, / No me haga ningún reproche: / También es negra la noche / $Y$ tiene estrellas que brillan" (vv. 4037 4048). Después de tantas afirmaciones de intención ejemplar con las que se sitúa el Moreno, cierra las declaraciones con un dato contradictorio: "Estoy, pues, a su mandado, / Empiece a echarme la sonda / Si gusta que le responda, / Aunque con lenguaje tosco:/En leturas no conozco / La jota por ser redonda" (vv. 4049-4054). Al rehacer el dicho popular, "no conocer la o por redonda", el negro cuestiona el dato de su aprendizaje junto a un fraile y los pregones de su sabiduría. Puede ser

4 La definición de El gaucho Martin Fierro concreta una disposición esencial del cantor entre los hombres: "Mi gloria es vivir tan libre / Como el pájaro del Cielo; / No hago nido en este suelo, / Ande hay tanto que sufrir; / Y naides me ha de seguir / Cuando yo remuento el vuelo". (vv. 91-96). En las presentaciones de los protagonistas abundan los paralelismos: Fierro-Cruz, Fierro-el Moreno, Hijo Mayor-Hijo Segundo-Picardía. 
una fórmula retórica de valoración disminutiva, que haría resaltar las virtudes del cantor contrapuestas a las declaraciones de modestia. También puede considerarse como una referencia implícita a que sus conocimientos derivan de la naturaleza, no de los libros. ${ }^{5}$

La primera pregunta de Fierro solicita a su contendiente la explicación de "Cuál es el canto del cielo". Antes de la respuesta, el Moreno retruca a quien lo ha llamado "negro"; la segunda de las sextillas sobre esta designación define la igualdad de todos los humanos: "Pinta el blanco negro al diablo, / Y el negro blanco lo pinta;/Blanca la cara o retinta, / No habla en contra ni en favor: / De los hombres el Criador/No hizo dos clases distintas" (vv. 4067-4072). De las cuatro estrofas del Moreno, una sola se refiere a la pregunta planteada: "Los cielos lloran y cantan / Hasta en el mayor silencio; / Lloran al cair el rocío, / Cantan al silbar los vientos, /Lloran cuando cain las aguas, / Cantan cuando brama el trueno" (vv. 4079-4084). A su vez, al aceptar la definición del Moreno, Fierro rectifica la generalización de su oponente: "Dios hizo al blanco y al negro / Sin declarar los mejores; / Les mandó iguales dolores / Bajo de una mesma cruz; / Más también hizo la luz / Pa distinguir los colores" (vv. 4085-4090). En instancia pri-

5 En las declaraciones del Moreno juega constantemente la distancia entre la sabiduría de que alardea y las confesiones de ignorancia intelectual; aunque estos vaivenes correspondan a un recurso propio del contrapunto, sorprende el dato de su educación a cargo de un fraile. En la primera de las gacetas de Aniceto el Gallo, 1853, Ascasubi resume la versación de su protagonista con estos datos: "yơ soy hombre corrido, sabido, leido y escribido, porque de charabón me agarró un flaire que confesaba a mi hermana, y me llevó al convento de San Francisco, adonde me enseñó hasta la mitá de la Bramática en latín, y el ayudar misa; y no aprendí la Jergrafía, porque le hice una juida al padre" (Poesía gaucbesca II. Edición, prólogo, notas y glosario de Jorge Luis Borges y Adolfo Bioy Casares. México, Fondo de Cultura Económica, 1955; p. 9). Ascasubi transfiere a Aniceto el Gallo las experiencias fundamentales de su trajinada vida; Hernández pudo leer el texto en la edición parisiense de las obras completas del autor, aparecida en 1872. Por otra parte, contemporáneos del creador de Paulino Lucero insisten en el color subido del poeta; Rafael Hernández, hermano de José, consigna: "El mulato Ascasubi, como el pueblo lo denominaba y en efecto no dejaba enteramente de parecerlo..." (Hernández, Rafael. Pebuajó. Nomenclatura dé las calles. Breve noticia sobre los poetas argentinos que en ellas se conmemoran. Buenos Aires, Imprenta de Obras de J. A. Berra, 1896; p. 46). En la misma biografía, los juicios sobre la actuación política y la producción literaria de Ascasubi apuntan reproches severos de quien coincidió regularmente con las ideas de su hermano. A propósito de la edición parisiense de Ascasubi se resume: "Los numerosos chistes que campeaban en las composiciones primitivas, aparecen desleídos en versos inútiles y las animadas descripciones languidecen sensiblemente, perdiendo su colorido y sabor criollo entre una versificación a veces amanerada, pues no habiendo sido nunca realmente gaucho, y alejado tantos años de los tipos que con verdadera maestría copió, su espíritu imitativo no podía resistir la acción del tiempo y el medio social en que vivía: así es que pagó con mengua de su fama el error muy explicable que cometió" (p. 49). Tales indicios podrían probar una alusión a Ascasubi en el Moreno del contrapunto. Cf.: Azeves, Ángel Héctor. Contribución al estudio dal "Martín Fierro". 1; El Moreno de la Payada; anotaciones marginales. La Plata, 1949. 
mera acepta la igualación propuesta por su oponente, pero la corrige desde el punto de vista racial que se desenvuelve en todas sus intervenciones. Frente al negro, Fierro prolonga la defensa polémica de los blancos ("los cristianos") que ya manifiesta en su visión de los indios pampas.

En la articulación del contrapunto, además de las cuestiones dirigidas al tequerido, van apareciendo referencias a la situación personal de ambos cantores. Las puyas de Fierro apuntan al color de su oponente y a sus cualidades de varón; lo confirma el avance de la payada. La segunda pregunta de Fierro ha inquirido: "Decíme cuál en el mundo/Es el canto de la tierra" (vv. 4101-4102). En la respuesta aparece la primera alusión a la cuestión personal pendiente entre ambos; el negro suma en el canto terreno "El dolor de tanta madre, / El gemir de los que mueren / Y el llotar de los que nacen" (vv. 4112-4114). Los dos primeros términos de la enumeración señalan al tema argumental que se aclara al final del contrapunto. El elogio de Fierro a la respuesta agrega este comentario: "Moreno, alvierto que trais / Bien dispuesta la garganta / Sos varón y no me espanta/Verte hacer esos primores: /En los pájaros cantores / Sólo el macho es el que canta" (vw. 4115-4120). A la vez que recoge la pregunta tercera - "Cuál es el canto del mar"-, el Moreno contesta a la alusión anterior: "A los pájaros cantores / Ninguno imitar pretende; / De un don que de otros depende / Naides se debe alabar, / Pues la urraca apriende hablar / Pero sólo la hembra apriende" (vv. 4126-4131). El canto de los pájaros es una dádiva divina; el Moreno reconoce que el suyo surge de una disposición humana, sujeta por tanto a sus límites; la referencia despectiva a la urraca señala la parlería sin sentido en las mujeres.

Las tensiones latentes en el canto van apuntando a motivos ocultos en la provocación; las alusiones permanentes mantienen la suspensión argumental propuesta por el desartollo del contrapunto. Fierro adivina la intención final del Moreno, pero espera que éste le adelante sus propósitos.

La posición personal del Moreno se refuerza en su respuesta a la pregunta cuarta de Fierro - "La noche tiene su canto, / Y me has de decir cuál es" (vv. 4149.4150)-; la contestación del negro concluye: "A las sombras sólo el sol/Las penetra y las impone; / En distintas direcciones / Se oyen rumores inciertos: / Son almas de los que han muerto, / Que nos piden oraciones" (vv. 4163-4168). El elogio del contendor suma la disposición personal del Moreno y su instrucción - "Pues tenés desposición / Y sos estruido de yapa; / Ni las sombras se te escapan/Para dar esplicación" (vv. 4171-4174) -; a la vez le recuerda 
que han de cantar, "Dejando en la paz de Dios / Las almas de los que han muerto" (vv. 4179-4180). La advertencia última se instala en un principio de validez genérica: "Siempre ha de ser comedida / La palabra de un cantor" (vv. 4183-4184). Fierro ha olvidado la actitud despectiva con que se ha estado dirigiendo a su oponente: basta reconocer las distancias en las fórmulas de tratamiento: al respetuoso "usted" del Moreno se opone el rebajador "vos" de Fierro, nunca utilizado con su amigo Cruz. Al final del enfrentamiento, Fierro precipita las expresiones despectivas, reduciendo así la importancia concedida a la valentía de su opositor, para culminar con los hirientes versos 4493-4510.

Las primeras cuatro preguntas de Fierro responden al plan de co. nocimiento de los misterios naturales propuesto por el Moreno en su presentación; las dos restantes atienden a las condiciones del hombre, sentimiento e inteligencia: "De dónde nace el amor" y "Lo que entendés por la ley". La respuesta a la primera relaciona románticamente el amor con el origen divino de la existencia, extendido al pájaro, la fiera, el pez y el hombre: "Ama todo cuanto vive; / De Dios vida se recibe, /Y donde hay vida hay amor" (vv. 4209-4210). La contestación a la segunda desdeña las "dotorerías" y busca una explicación social directa: "La ley es tela de araña, / En mi inorancia lo esplico. / No la tema el hombre rico, / Nunca la tema el que mande, / Pues la ruempe el bicho grande / Y sólo enrieda a los chicos' (vv. 4235-4240). Al llegar al planteo último, el Moreno se acerca al canto con opinión, extendiendo su protesta a la situación marginal de los pobres, para concluir con una generalización crítica sobre el manejo parcializado de las leyes: "Hay muchos que son dotores, $/ Y$ de su cencia no dudo, / $Y$ aunque de esto poco entiendo, / Estoy diariamente viendo / Que aplican la del embudo" (vv. 4253-4258). Coincidencia con un tema de los gauchescos, reiterado desde los Díllogos patrióticos de Bartolomé Hidalgo.

Dadas satisfactoriamente las respuestas por el Moreno, Fierro lo elogia a causa de la experiencia vital y la lucidez de sus conocimientos: "Has aprovechao la vida" (v. 4261); "Que sos por juera tinieblas / Y por dentro claridá" (vv. 4269-4270). Cerrada la parte primera de sus inquisiciones, da licencia al contendente para que le pregunte; el Moreno adelanta los temas de su interrogatorio: "Voy a hacerle mis preguntas, / Ya que a tanto me convida; / Y vencerá en la partida / Si una esplicación me da / Sobre el tiempo y la medida, / El peso y la cantidá" (vv. 4283-4288). Refuerza su interés indicando que esas definiciones no están en las fuentes de su conocimiento: "Quiero saber y lo inoro, / Pues en mis libros no está / $Y$ su respuesta vendrá / A servirme de gobierno: / Para qué fin el Eterno/Ha criado la cantidad" (vv. 4295-4300). El 
negro supone que tales nociones son una creación de la sabiduría divina; las respuestas de Fierro insisten en caracterizarlas como intervenciones decisivas de la inteligencia humana; una forma de instalación en el universo de la criatura más perfecta. La primera respuesta adelanta el sistema explicativo de las restantes: "Uno es el sol, uno el mundo, / Sola y única es la luna; / Ansí, han de saber que Dios / No crió cantidá ninguna. / El ser de todos los seres / Sólo formó la unidá; / Lo demás lo ha criado el hombre / Después que aprendió a contar" (vv. 4305-4314). Idea extendida a las contestaciones siguientes: "La medida la inventó / El hombre para bien suyo (vv. 4323-4324); "Dende que hay bienes y males / Fue el peso para pesar / Las culpas de los mortales" (vv. 4340-4342); "Porque el tiempo es una rueda, / Y rueda es eternidá; / Y si el hombre lo divide / Sólo lo hace, en mi sentir, / Por saber lo que ha vivido / O le resta por vivir" (vv. 4355-4360). A la definición de la medida, corresponde un elogio abarcador del Moreno: "Si no falla su saber / Por ven. cedor lo confieso; / Debe aprender todo eso / Quien a cantar se dedique" (vv. 4329-4332). Indica así el valor de los temas abstractos, situados en la escala más alta de la sabiduría payadoresca.

Una vez aclaradas las cuatro perplejidades propuestas por el negro, Fierro renueva el nivel de la payada alejándose con decisión de las cuestiones planteadas anteriormente. Su reclamo acomoda el contrapunto a las disposiciones civilizadoras que modulan el aspecto moral de La vuelta de Mintin Fierro: "No procedo por soberbia/Ni tampoco por jactancia, / Mas no ha de faltar constancia / Cuando es preciso luchar; / Y te convido a cantar / Sobre cosas de la Estancia". (vv. 4367-4372). Las preguntas de Fierro fueron moduladas sobre la justificación de los temas adelantados por el Moreno; las de éste se fijaron en una temática abstracta, reducida por su opononte al denominador humano. Aunque Fierro ha contestado satisfactoriamente, no da por concluida la payada y la reabre con un cambio de actitud, acomodado al plan desenvuelto por las declaraciones que prologan la parte segunda del poema: "Me has de decir lo que empriende / El que del tiempo depende, / En los mieses que train erre" (vv. 4376-4378).$^{6}$

Ante el nuevo planteo de Fierro, el Moreno acepta su derrota, alegando su falta de cultura libresca: "He declarao que en leturas / Soy

6 En sus notas a Martín Fierro, Tiscornia transcribe pasajes del propio Hernández en que se pormenoriza la respuesta a esa pregunta: Hernández, José. Instrucción del Estanciero. Tratado completo para la planteación y manejo de un establecimiento de campo destinado a la cría de la bacienda vacuna, lanar y caballar. Buenos Aires, C. Casavalle, 1884; pp. 165, 189, 156, 301, 303, 311, etcétera (En: Hernández, José. Martín Fierro. Comentarios, notas y vocabulario de Eleu. terio F. Tiscornia. Madrid, Aguilar, 1971; pp. 475-476). 
redondo como jota; / No avergüence mi redota, / Pues con claridá lo digo: / No me gusta que conmigo/Naides juegue a la pelota" (vv. 4385-4390). El interrogado se escapa así de la experiencia a que apunta la inquisición de Fierro; la salida del Moreno cubre mal su ignorancia de las tareas del campo organizado en estancias. ${ }^{7}$

A la vez que certifica su situación de "pobre cantor vencido", el Moreno adelanta su conducta para el futuro: "Y dende hoy en adelante, / Pongo de testigo al cielo/Para decir sin recelo/Que, si mi pecho se inflama, / No cantaré por la fama / Sinó por buscar consuelo" (vv. 4409-4414). En el aceptamiento de su derrota insiste en la difusión del prestigio social que acompaña a los payadores de buena ley; esta determinación señala el carácter eminentemente profesional del cantor, con la exigencia de un público celebrador de sus virtudes. De la previsión para su futuro surge la negación del destino de cielo con que había definido los alcances de su libertad: "Y este triste desengaño / Me durará mientras viva; / Aunque un consuelo reciba/Jamás he de alzar el vuelo: / Quien no nace para el cielo / De balde es que mire arriba" (vv. 4421-4426).

Concluido el desartollo del contrapunto, el Moreno se dirige al auditorio para revelas: el sentido final de su encuentro con Fierro: "Y suplico a cuantos me oigan / Que me permitan decir / Que al decidirme a venir / No sólo jue por cantar, / Sinó porque tenga a más / Otro deber que cumplir" (vv. 4427-4432). Esta misión es la venganza de la muerte de su hermano mayor, sacrificado por injustos modos "A mano de un pendenciero" (v. 4438). Fierro acepta el nuevo desafío, instalándolo en "La ley de su destino"; la recapitulación de sus desdichas incluye el enfrentamiento con el vengador: "Primero fue la frontera/Por persecución de un Juez, / Los indios fueron después, / Y, para nuevos estrenos, / Aura son estos morenos / Pa alivio de mi vejez" (vv. 4487-4492). Acorde con esta posición y precipitando los hechos, insulta al negro; después declata que ya no busca "peleas", aunque insista en la persistencia de su valentía personal: "Las contiendas no me gustan; / Pero ni sombras me asustan / Ni bultos que se menean" (vv. 4514-4516).

El romance del canto 31 , en la voz del poeta, informa de la intervención de los presentes, quienes evitan el propuesto duelo a cuchillo; olvidando al Moreno, los versos se centran en Martín Fierro, sus dos

7 ¿Puede ser una referencia al desconocimiento de la vida rural que Hernández dirige al Ascasubi de Santos Vega o Los mellizos de la Flor? Las contradicciones del Moreno y ciertas actitudes de Fierro apuntan a una situación personal que supera el antagonismo de ambos protagonistas y se proyecta a una diferencia planteada fuera del poema. Los biógrafos de Hernández y los de Ascasubi no aportan datos sobre las relaciones entre ambos. 
hijos y el de Cruz. Estos se tetiran al campo con tranquilidad que sitúa la salida a distancia de una fuga: "Evitando la contienda, / Montaron y paso a paso / Como el que miedo no lleva, / A la costa de un arroyo / Llegaton a echar pie a tierra" (vv. 4530-4534).

En la composición de La vuelta de Martín Fierro el contrapunto coincide en ilustrat dos motivos: la transformación moral del protagonista primero y la ampliación de los cuadros costumbristas que sitúan su nueva trayectoria poemática en relación con las dimensiones de la sociedad campesina. En el desarrollo del argumento interesa fundamentalmente el final del episodio. Por vez primera en las dos partes de Martín Fierro, el protagonista supedita sus actos a la intervención de los otros, el auditorio que ha seguido el contrapunto; "Procurando los presentes / Que no se armara pendencia, / Se pusieron de por medio / Y la cosa quedó quieta" (vv. 4525-4528). De esta manera se prepara la lección moral desenvuelta por sus "Consejos" finales, con la abundancia de direcciones docentes abiertas por el canto 32. Los años duros entre los pampas han transformado el carácter de Fierro, alejándolo de los impulsos que determinan la muette del negro en la parte primera.

En El gaucbo Martín Fierro el episodio del canto VII presenta al protagonista en una situación especial, explicando así actos no justificables: "Riunidos al pericón / Tantos amigos hallé, / Que alegre de verme entre ellos / Esa noche me apedé. // Como nunca en la ocasión / Por peliar me dio la tranca, / Y la emprendí con un negro / Que trujo una negra en ancas" (wv. 1143-1150). Los efectos de la bebida están en el origen de la provocación y del duelo; las ocho estrofas últimas del canto oscilan entre una actitud todavía rencorosa del protagonista y ciertos rasgos de remordimiento. En La vuelta de Martín Fierro los cantos 1 a 10 van preparando la maduración moral que sostiene la dirección ejemplar de los "Consejos" de Fierro, rubricados por las alusiones a la experiencia vital y el efecto de los años desventurados: "Yo nunca tuve otra escuela / Que una vida desgraciada" (vv. 4601-4602); "El hombre no mate al hombre / Ni pelee por fantasía; / Tiene en la desgracia mía / Un espejo en que mirarse: / Saber el hombre guardarse / Es la gran sabiduría" (vv. 4733-4738). El poeta necesita que la moraleja no aparezca en contradicción con los actos de Fierro; la amistad con Cruz, afianzada en el período de "cautivos", y el rescate de la Cautiva coinciden con su reacción final frente al Moreno provocador. A pesar de estos episodios, ciertos rasgos caracterizadores de Fierro en la primera parte reaparecen en sus intervenciones del canto 30 de la segunda.

En la trayectoria protagónica de Fierro, el canto 30 de La vuelta de Martín Fierro lo reintegra a sus funciones de cantor, suspendidas por la 
condición de oyente pasivo en que se encuentra frente a los relatos del Hijo Mayor, del Hijo Segundo y de Picardía. En el contrapunto se exponen además dos temáticas de este estilo de payar: mientras el Moreno se mantiene en la visión de los fenómenos de la naturaleza y se preocupa por cuestiones abstractas, Fierro busca argumentos en las condiciones del hombre y se abre a una caracterización de la vida rural organizada. Tal distingo atribuye a Fierro un pragmatismo docente, ajustado al interés civilizador del nuevo poema.

Los cuadros costumbristas de la segunda parte abarcan un diseño amplio de la existencia campesina a través de personajes diversos y situaciones distintas. Con estos elementos se sitúa el contorno social de los protagonistas y se refuerza la aproximación a los lectores reclamados por el prólogo, los hombres de campo, a quienes se les ofrece un libro adecuado a su comprensión. ${ }^{8}$ La payada de contrapunto era entretención habitual entre los gauchos, una de las formas de su vida social, y el autor podía lucirse con las posibilidades de sus caracteres, abriendo al mismo tiempo los elementos argumentales que preparan el final admonitorio.

En el desarrollo total de Martin Fierro el contrapunto se sitúa como una proyección de los cantores populares de producción oral en la gauchesca; resulta así una forma ilustrativa de la concepción del mundo divulgada por los versificadores en despliegue consecuente de su filos ofía de la vida, tan válida para hombres educados por las relaciones con la naturaleza y por las desventuras propias de su clase.

Ricardo Rojas dio categoría literaria al término "gauchesco", designando con él al poeta ciudadano y letrado, que desarrollaba temas rústicos en el supuesto lenguaje oral de los campesinos y difundía su obra a través de textos impresos. Ya estál así latente la distinción con respecto a los autores anónimos que cantaban en lenguaje común, con marcadas pretensiones literarias. En busca de una afirmación de la originalidad telúrica de la gauchesca, en el tomo I de La literatura argentina, Rojas

8 Las "Cuatro palabras de conversación con los lectores" que prolongan La vuelta de Martín Fierro definen el texto como dirigido raigalmente a los lectores campesinos: "Un libro destinado a despertar la inteligencia y el amor a la lectura en una población casi primitiva, a servir de provechoso recreo, después de las fatigosas tareas, a millares de personas que jamás han leído, debe ajustarse estrictamente a los usos y costumbres de esos mismos lectores, rendir sus ideas e interpretar sus sentimientos en su mismo lenguaje, en sus frases más usuales, en su forma más general, aunque sea incorrecta; con sus imágenes de mayor relieve, $y$ con sus giros más característicos, a fin de que el libro se identifique con ellos de una manera tan estrecha e íntima, que su lectura no sea sino una continuación natural de su existencia". El autor busca que los lectores se integren con el auditorio que en el poema sigue las relaciones y el contrapunto; este propósito cumpliría sus deseos de borrar los deslindes entre vida y literatura. 
reunió un material de ejemplos que busca servir de sustento a las relaciones de los poetas cultos con el folklore poético. ${ }^{9}$

Como una consecuencia de los textos folklóricos aportados por Rojas, se buscó una distinción simplista para cubrit las diferencias entre las "relaciones" autobiográficas de los distintos protagonistas de Martin Fierro, supuestamente ajenas a la tradición popular, y el contrapunto entre Fierro y el Moreno, que propondría un texto relacionado con una forma de canto prolongada hasta principios de este siglo. Con un criterio primario la escritura mayoritaria del texto se relacionó con una tradición literaria, la de los gauchescos, válida para Hernández desde las composiciones de Hidalgo, a quien se recuerda en la carta prólogo de la parte primera. ${ }^{10}$ En cambio el contrapunto se explicó como una proyección de

9 Rojas, Ricardo. Ia literatura argentina. Ensayo filosófico sobre la evolución de la cultura en el Plata. I, Los gauchescos. Buenos Aires, Imprenta de Coni Hermanos, 1917; pp. 123-145, 164-256. Cf.: Cortazar, Augusto Raúl. Poesía gaucbesca argentina. Interpretada con el aporte de la teoria folklorica. Buenos Aires, Editorial Guadalupe, 1969.

Federico de Onís fue el primero en llamar la atención sobre las diferencias entre los textos folklóticos allegados por Rojas y Mantin Fierro: "Leyendo "los capítulos que Rojas dedica a la poesía popular, en los que publica bastantes obras recogidas de la tradición oral, encontramos muchos datos que interesan al folklorista: cantares, refranes, supersticiones, etc., que, naturalmente, perteneciendo como pertenecen al pueblo argentino forman la materia bruta de una obra de inspiración popular como el Martin Fierro. Pero no aparece ninguna obra de inspiración popular que ni remotamente pueda ser modelo o preparación de la obra de Hernández. Se observan cantares y poesías breves de carácter lírico, recogidas de la tradición oral, que representan algunos de los tipos populares que imitaron los poetas gauchescos "literarios". Pero Rojas no publica ningún canto natrativo extenso, recogido de la tradición oral, que pudieta considerarse como ejemplo de poesia popular que Hernández tuvo presente al escribir su poema, y que preparase el advenimiento de éste. Entre la materia informe folklótica y la unidad profunda del gran poema de Hernández parece no habet nada, y que, por lo tanto, Hernández es el creador total de su obra, sin intervención alguna del pueblo argentino" (Onís, Federico de. "El "Martín Fierro' y la poesía tradicional" (En: Homenaje ofrecido a Menéndez Pidal. Miscelanea de estudios lingǘsticos, literarios e bistóricos. Madrid, Hernando, 1926; t. II, p. 410) ). V.: Fernándéz Latout de Botas, Olga. "Federico de Onís, vigencia de sus planteos sobre 'El Martín Fierro' y la poesia tradicional (En: Marín Fierro un siglo. Buenos Aires, Editorial Xerox, Argentina, 1972; pp. 57-66).

10 Hernández nombra un texto de Hidalgo y otro de Del Campo —con significativo olvido de Ascasubi-, para señalat las diferencias de su obra: "Martin Fierro no va de la ciudad a teferir a sus compañeros lo que ha visto y admirado en un 25 de Mayo y otra función semejante, referencias algunas de las cuales, como el Fausto y varias otras, son de mucho mérito ciertamente, sino que cuenta sus trabajos, sus desgracias, los azares de su vida de gaucho, y vd. no desconoce que el asunto es más difícil de lo que muchos se lo imaginan". La insistencia en los distingos sobre las coincidencias revela la constancia del autor en la composición de su poema y aclara sus relaciones parciales con los gauchescos anteriores. Los Diálogos patrióticos de Hidalgo levantan ya una forma de canto con opinión, destinado a defender la igualdad de los gauchos en el panorama social argentino y a dirigir sus críticas a los gobernantes que los olvidaban. Este cantar con fundamento fue parcializado por Ascasubi, al convertir a sus protagonistas en voceros de un partido: el de la oposición a Juan Manuel de Rosas primero, y a Justo José de Urquiza después; opción partidista que incluye la 
la actividad de los payadores. Con esta diferencia, el poeta habría situado en un texto gauchesco la recreación de una modalidad popular. ${ }^{11}$

Las investigaciones de Olga Fernández Latour han cuestionado definitivamente tal tipo de explicaciones; sus estudios han descubierto y comentado "argumentos" criollos de trasmisión oral, coincidencias con temas de la composición hernandiana. ${ }^{12}$ Los textos publicados por Olga Fernández Latour se asemejan al que evoca Sarmiento en su arquetipo del "cantor" presentado por el capítulo II de Facundo - "Originalidad y caracteres argentinos" - junto al rastreador, el baqueano y el gaucho malo. ${ }^{13}$

sátira a los jefes del sector repudiado y a sus adherentes populares. Un aspecto de la obra de Del Campo, "Gobierno gaucho", vuelve a la actitud de Hidalgo, reiterando el canto de testimonio y denuncia. Ninguno de estos tres autores se había propuesto un poema extenso en que destinos distintos ejemplificaran una situación social condenable. Santos Vega o Los mellizos de La Flor, de Ascasubi, con edición completa en 1872 , se fija en otros aspectos de la vida rural, ligando el folletín romántico con el costumbrismo aplicado a cvocar la supuesta edad de oro de los gauchos, sin que por estas relaciones literarias se anulen las que lo proyectan en referencia al folklore poético.

$11 \mathrm{La}$ interpretación borgiana del contrapunto entre Fierro y el Moreno abre una perspectiva ficcional muy amplia: "Aquí nos aguarda uno de los episodios más dramáticos y complejos de la obra que estudiamos. Hay en todo él una singular gravedad y está como cargado de destino. Trátase de una payada de contrapunto, porque así como el escenario de Hamlet encierra otro escenario, y el largo sueño de las Mil y una nocbes, otros sueños menores, el Martín Fierro, que es una payada, encierra otras. Ésta, de todas, es la más memorable". Sobre su argumento comenta una hipótesis probatoria de la fuerza del encuentro entre los dos cantores: "Rojas ha interpretado literalmente la palabra fantástico y ha visto en el moreno algo así como la voz de la conciencia. Entiendo que esta conjetura es errónea, pero el hecho de que haya sido formulada es una prueba de la tensión dramática del pasaje. El desafío del moreno incluye otro, cuya gravitación creciente sentimos, y prepara o prefigura otra cosa, que luego no sucede o que sucede más allá del poema" (Borges, Jorge Luis y Margarita Guerreto. El "Mattin Fierro". Buenos Aires, Editorial Columba, 1953; p. 61). Borges aprovechó esas sugerencias en su cuento "El fin", incluido en la segunda edición de Ficciones: relata un nuevo encuentro entre Fierro y el Moreno, esta vez en duelo a cuchillo, con el triunfo del segundo en la plenitud de su misión. "Cumplida su tarea de justiciero, ahora era nadie. Mejor dicho era el otro: no tenía destino sobre la tierra y había matado a un hombre" (Borges, Jorge Luis. Ficciones. Buenos Aires, Emecé Editores, 1956; pp. 177-180. La cita, de la p. 180).

12 V.: Fernández Latour, Olga. "El 'Martín Fierro' y el folklore poético" (En: Cuadernos del Instituto Nacional de Investigaciones Folklóricas, No. 3. Bưenos Aires, Ministerio de Educación y Justicia, 1962; pp. 287-308). Cf.: Fernández Latour de Botas, Olga. Folklore y poesía argentina. Buenos Aires, Editorial Guadalupe, 1969.

13 "El gaucbo cantor es el mismo bardo, el vate, el trovador de la edad media, que se mueve en la misma escena, entre las luchas de las ciudades y el feudalismo de los campos, entre la vida que se va y la vida que se acerca. El cantor anda de pago en pago, 'de tapera en galpón', cantando sus héroes de la pampa, perseguidos por la justicia, los llantos de la viuda a quien los indios robaron sus hijos en un malón reciente, la derrota y la muerte del valiente Rauch, la catástrofe de Facundo Quiroga, y la suerte que cupo a Santos Pérez". En la visión genérica se instala un caso particular: "En el año 1840, entre un grupo de gauchos y a orillas del majestuoso Paraná, estaba sentado en el suelo y con las piernas cruzadas un cantor que tenía azorado y divertido a su auditorio con la larga y animada historia de sus trabajos y aventuras. Había ya contado lo del rapto de su querida, con los trabajos 
Con gran difusión en distintas provincias argentinas, los cantares son habitualmente historias de desertores, proscriptos y perseguidos; hombres marginados de la sociedad y acosados por las fuerzas policiales. Con ciertos resabios de fatalismo matonesco, sus temas se aproximan a pasajes de las relaciones centrales de Martín Fierro, pero se diferencian fundamentalmente de la creación hernandiana en la no utilización del habla gauchesca.

A partir del folklore poético, el autor de Martin Fierro habría contado entonces con dos tipos de estímulos: el relato de destinos desgraciados - paisanos perseguidos por la policía- y el canto de contrapunto - -sobre temas generales o abstractos, aunque no faltaran las referencias personales a la condición de los payadores. Si todo el poema puede ser considerado como una sucesión de relaciones argumentales, sostenida por las voces de los distintos protagonistas -entre los cuales se sitúa el poeta-, el contrapunto expone una variedad competitiva del canto gaucho. Ambas formas han sido transformadas por la composición de Hernández, con lealtad a las hablas presumiblemente rurales de sus protagonistas. Tales rasgos se reducen en el enfrentamiento de Fierro con el Moreno, como disminuyen en las reflexiones morales del Hijo Mayor y en los "Consejos" de Fierro.

El gaucho cantor de la tradición popular quería clevarse sobre su lengua cotidiana, buscando el acercamiento a un estilo retórico, por cuestionables que fueran sus relaciones con los modelos de la poesía culta contemporánea. Por el contrario, los gauchescos trataron de enaltecer los matices rústicos del idioma, sin desnaturalizar desajustes y anarquías. Hernández fue el poeta que solucionó con lucidez mayor ese planteo estilístico, alcanzando a través de su escritura una nitidez esencial en la caracterización variada de sus personajes. Los juicios laudatorios de los hombres públicos y de los intelectuales contemporáneos de la aparición de las dos partes de Martin Fierro no ignotaron la lealtad al tipo social que se evocaba. ${ }^{14}$

Cualquiera sea la procedencia de sus estímulos, Hernández confirma regularmente la originalidad de su escritura. Un estilo que resella las incitaciones con la validez de los predicados propuestos ya en la carta

que sufrió; lo de la desgracia, y la disputa que la movió; estaba refiriendo su encuentro con la partida y las puñaladas que en su defensa dio, cuando el tropel y los gritos de los soldados le avisaron que esta vez estaba cercado" (Sarmiento, Domingo Faustino. Facundo. Edición crítica y documentada. Prólogo de Alberto Palcos. La Plata (Rep. Argentina), Universidad Nacional de La Plata, 1938; pp. 61 y 62). Se ha modernizado la ortografía.

14 V.: "Apéndice documental" (En: Martín Fierro un siglo; pp. 185-242). Se reproducen juicios de Miguel Cané, Bartolomé Mitre, Nicolás, Avellaneda, Ricardo Palma, Juana Manuela Gorriti, José Tomás Guido, Adolfo Saldias, etcétera. 
al Señor D. José Zoilo Miguens que encabeza la parte primera: "Me he esforzado, sin presumir haberlo conseguido, en presentar un tipo que personificara el carácter de nuestros gauchos, concentrando el modo de ser, de sentir, de pensar y de expresarse que les es peculiar; dotándolo con todos los juegos de su imaginación llena de imágenes y de colorido, con todos los arranques de su altivez, inmoderados hasta el crimen, y con todos los impulsos y arrebatos, hijos de la naturaleza que la educación no ha pulido y suavizado".

Atento a sus principios, el contrapunto de La vuelta de Martín Fierro ejemplifica una de las actuaciones más celebradas de los payadores: el canto competitivo apoyado en versiones del universo mundo y de la condición humana. Una sabiduría derivada de la naturaleza y de la reflexión de los dolores propios es la fuente emotiva de esos cantores; los recursos retóricos subrayan la voluntad literaria latente en la exhibición que juega frente al auditotio la fama de los oponentes, ya con su modelo mítico en la trayectoria simbólica de Santos Vega.

Las diferencias entre los relatos de vidas desdichadas, torcidas por los malos representantes de la justicia y de la autoridad, y las definiciones genéricas del contrapunto son renovadas desde las perspectivas hernandianas, tan lúcidas en sus simpatías y sus diferencias con el folklore poético y con la tradición de la gauchesca.

Juan Carlos Ghiano

Universidad Nacional de La Plata

(Argentina) 
